\title{
Sources of 21st century regional sea-level rise along the coast of northwest Europe
}

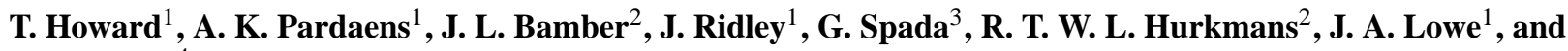 \\ D. Vaughan 4 \\ ${ }^{1}$ Met Office Hadley Centre, FitzRoy Road, Exeter, EX13PB, UK \\ ${ }^{2}$ Bristol Glaciology Centre, School of Geographical Sciences, University of Bristol, University Road, Bristol, BS8 1SS, UK \\ ${ }^{3}$ Dipartimento di Scienze di Base e Fondamenti, Urbino University “Carlo Bo”, Via Santa Chiara, 27, 61029 Urbino (PU), \\ Italy \\ ${ }^{4}$ British Antarctic Survey, Madingley Road, High Cross, Cambridge, CB3 0ET, UK \\ Correspondence to: T. Howard (tom.howard@metoffice.gov.uk)
}

Received: 29 November 2013 - Published in Ocean Sci. Discuss.: 17 December 2013

Revised: 1 April 2014 - Accepted: 3 April 2014 - Published: 19 June 2014

\begin{abstract}
Changes in both global and regional mean sea level, and changes in the magnitude of extreme flood heights, are the result of a combination of several distinct contributions most, but not all, of which are associated with climate change. These contributions include effects in the solid earth, gravity field, changes in ocean mass due to ice loss from ice sheets and glaciers, thermal expansion, alterations in ocean circulation driven by climate change and changing freshwater fluxes, and the intensity of storm surges. Due to the diverse range of models required to simulate these systems, the contributions to sea-level change have usually been discussed in isolation rather than in one self-consistent assessment. Focusing on the coastline of northwest Europe, we consider all the processes mentioned above and their relative impact on 21 st century regional mean sea levels and the 50-year return flood height. As far as possible our projections of change are derived from process-based models forced by the A1B emissions scenario to provide a self-consistent comparison of the contributions. We address uncertainty by considering both a mid-range and an illustrative high-end combination of the different components.

For our mid-range ice loss scenario we find that thermal expansion of seawater is the dominant contributor to change in northwest European sea level by 2100 . However, the projected contribution to extreme sea level, due to changes in storminess alone, is in some places significant and comparable to the global mean contribution of thermal expansion. For example, under the A1B emissions scenario, by 2100, change
\end{abstract}

in storminess contributes around $15 \mathrm{~cm}$ to the increase in projected height of the 50-year storm surge on the west coast of the Jutland Peninsula, compared with a contribution of around $22 \mathrm{~cm}$ due to thermal expansion and a total of $58 \mathrm{~cm}$ from all of the contributions we consider. An illustrative combination of our high-end projections suggests increases in the 50-year return level of $86 \mathrm{~cm}$ at Sheerness, $95 \mathrm{~cm}$ at Roscoff, $106 \mathrm{~cm}$ at Esbjerg, and $67 \mathrm{~cm}$ at Bergen. The notable regional differences between these locations arise primarily from differences in the rates of vertical land movement and changes in storminess.

\section{Introduction}

In recent years, several scientific communities have put considerable effort into establishing projections of the various individual contributions to global mean sea-level rise. These include: projections of thermal expansion of the oceans (e.g. Kuhlbrot and Gregory, 2012); ice loss from Antarctica (e.g. Vizcaíno et al., 2010, Ligtenberg et al., 2013), Greenland (e.g. Goelzer et al., 2013; Nick et al., 2013; Shannon et al., 2013) and mountain glaciers (e.g. Giesen and Oerlemans, 2013); and from changes in the terrestrial storage of water as ground water and in reservoirs (e.g. Lempérière, 2006).

At intervals, these efforts have been usefully consolidated into "consensus" projections of global mean sea-level rise by the Intergovernmental Panel on Climate Change (IPCC; 
e.g. Church et al., 2013), which have guided the global debate on options for adaptation to, and mitigation of, the impacts of climate change. Rather less effort has gone into understanding the complex processes that modify global mean sea level to give regional sea-level changes, which include vertical land movements, changes in the Earth's gravity field, regional variations in thermal expansion, and changes in ocean circulation and changing freshwater fluxes driven by climate change. Very few studies indeed have attempted to produce projections of changes in extreme sea level (i.e. that experienced during occasional damaging storm events), although it is well known that the most acute impacts of sea-level change on coastal communities, assets and environments can be best understood through changes in the severity and/or frequency of such extreme events (Lowe and Gregory, 2005). On a global scale these changes are dominated by changes in mean sea level (e.g. Woodworth and Blackman, 2004), but on a local scale changes in atmospheric circulation, and the consequent impact on the generation of storm surges, may also be significant.

A valuable metric in understanding these potential impacts is the change in height of the highest sea level experienced during a storm over a particular return period. For example, a change in the height of the most extreme storm surge expected once in every 50-year period, the so-called 50-year storm surge, gives a good indication of the increase in flood risk for a particular portion of coastline.

One key study, by Katsman et al. (2011), examined this issue for the Netherlands coastline, and further included the potential that river discharge will exacerbate problems in coastal flood defence. Their study used various sources for the contributions to sea level and storminess. Some contributions were based on process-based models tied to specific emissions scenarios, but others, specifically the contributions from ice loss, were based on extrapolation of short time series of observations. In addition, that study focused on the Dutch coastline, without a consideration of how the various contributions varied across a wider geographical area. A more recent study made a global assessment of regional variations in sea level (Slangen et al., 2012) but excluded a number of the processes mentioned above. In particular, they did not incorporate freshwater forcing, storm surge changes, or process-based model estimates of ice sheet contributions.

Other European studies, based on limited spatial areas, have found that the high natural variability in water level makes detection of trends in the extremes problematic. Haigh et al. (2010), for example, considered data from 18 sites around the English Channel and found changes in extreme water level similar to rates of observed mean sealevel change over the 20th century. Araújo and Pugh (2008) reached a similar conclusion for Newlyn in the UK, based on data from 1915 to 2005. For a recent review of past changes in factors contributing to extreme sea levels in the North Sea, see Weisse et al. (2012).
In this study, we use projections of regional sea-level change arising from 21 st century ice loss from ice sheets and glaciers (Spada et al., 2013; Howard et al., 2014), including the effects of changes to the gravity field and Earth rotation. We also include modelled changes in the climate of storm surges produced in support of the UK Climate Projections, Marine and Coastal Projections 2009 (UKCP09; Lowe et al., 2009) - a project to investigate the projected major contributions to 21 st century change in coastal flood risk and shelfsea hydrology around the coast of the United Kingdom. The UKCP09 project included both a (primarily process-based) ensemble projection of sea-level change and a proxy-based assessment of plausible upper limits (the so-called "H++" scenario). Their ensemble analysis gave projections of UK coastal geocentric sea-level rise of 13 to $60 \mathrm{~cm}$ over the $21 \mathrm{st}$ century (5th to 95th percentile, not including vertical land movement or changes in the climate of storm surges) under the A1B emissions scenario. The corresponding figure from the "upper end" of their $\mathrm{H}++$ scenario range was $190 \mathrm{~cm}$. Here we extend the UKCP09 approach to include more of the northwest (NW) European coast, and we augment the UKCP09 results with new process-based ice-melt projections.

In addition to the sources of sea-level variability listed above, we include projected contributions from thermal expansion, changes in dynamic sea level associated with the freshwater flux from ice melt, changes in dynamic sea level associated with projected global warming under the A1B emissions scenario, and projected changes in relative sea level due to vertical land movements arising from ice loss since the Last Glacial Maximum, termed glacial isostatic adjustment (GIA).

Our aim is to provide a comparison of geographic variations and uncertainties in the different contributions to NW European sea level. To do this we consider two scenarios for 21 st century change. The first, which we describe as a "midrange projection", is taken from close to the middle of the uncertainty range for each process considered. The second, which we describe as a "high-end projection", is taken from the upper end of the distribution. For contributions $T E, A D S L$ and $S R G$ (TE: Global mean thermal expansion of the ocean, $A D S L$ : Regional changes in dynamic sea level for A1B emissions scenario, excluding the effects of ice loss determined in offline models; SRG: Local 21st century change in 50-year return level of storm (skew) surge associated with changes in atmospheric storminess under the A1B scenario; see Table 1 for summary of all such abbreviations), these two scenarios represent the 50th and 95th percentiles respectively of an ensemble of projections to which we fitted a normal distribution (see Sect. 3.3). For the other contributions, we do not have access to a substantial ensemble of projections, and so we cannot specify percentiles. For these, the mid-range projection gives a representative estimate, and the high-end projection gives an illustrative measure of the upper end of the range of possible outcomes, based on a combination of 
Table 1. Summary of the contributions to 21 st century sea-level change included in this study.

\begin{tabular}{|c|c|c|}
\hline Abbreviation & Description & Source \\
\hline$T E$ & $\begin{array}{l}\text { Global mean thermal expansion of the } \\
\text { ocean }\end{array}$ & $\begin{array}{l}\text { Developed herein following Lowe et } \\
\text { al. (2009) }\end{array}$ \\
\hline$T I M$ & $\begin{array}{l}\text { Global mean terrestrial ice melt from } \\
\text { offline ice models }\end{array}$ & Howard et al. (2014) \\
\hline$G C F F$ & $\begin{array}{l}\text { Gravitationally consistent fingerprint } \\
\text { of projected future ice melt from of- } \\
\text { fline ice models (fast elastic lithosphere } \\
\text { response) expressed as departures from } \\
\text { the global mean }\end{array}$ & SELEN, Spada and Stocchi (2007) \\
\hline GIA & $\begin{array}{l}\text { Ongoing vertical land movement, due } \\
\text { to glacial isostatic adjustment (slow } \\
\text { viscous lithosphere response) }\end{array}$ & ICE-5G(VM2) Peltier (2004) \\
\hline IDSL (DSL due to ice) & $\begin{array}{l}\text { Regional changes in dynamic sea level } \\
\text { associated with the freshwater forc- } \\
\text { ing from ice loss determined in offline } \\
\text { models }\end{array}$ & $\begin{array}{l}\text { HadCM3, Howard et al. (2014) and } \\
\text { refs therein }\end{array}$ \\
\hline$A D S L$ ( $D S L$ directly due to $A 1 B)$ & $\begin{array}{l}\text { Regional changes in dynamic sea level } \\
\text { for A1B emissions scenario, excluding } \\
\text { the effects of ice loss determined in of- } \\
\text { fline models }\end{array}$ & $\begin{array}{l}\text { Developed herein following Lowe et } \\
\text { al. (2009) }\end{array}$ \\
\hline$S R G$ & $\begin{array}{l}\text { Local } 21 \text { st century change in } 50 \text {-year } \\
\text { return level of storm (skew) surge as- } \\
\text { sociated with changes in atmospheric } \\
\text { storminess under the A1B scenario }\end{array}$ & $\begin{array}{l}\text { HadCM3 PPE downscaled with CS3, } \\
\text { Lowe et al. (2009) and references } \\
\text { therein }\end{array}$ \\
\hline
\end{tabular}

our expert judgement (see Sect. 3.2) and analysis of processbased models. The one exception to this is the contribution from GIA, for which we present only a single modelled estimate.

Some of the factors not included in this study, but which may contribute to changes in extreme sea level, include changes in terrestrial water storage (e.g. Lettenmaier and Milly, 2009), changes in the climate of waves and swell (e.g. Lowe et al., 2009), changes in the tidal constituents or tidal range (e.g. Mudersbach et al., 2013; Woodworth, 2010; Müller et al., 2011; Pickering et al., 2012) and changes in the seasonal cycle (e.g. Wahl et al., 2014).

\section{Nomenclature}

We use the abbreviations MR and HE to refer to the representative mid-range and illustrative high-end model projections throughout. "MME" (Multi-Model Ensemble) refers to the ensemble based on some, or all, of the models that contributed data to the Climate Model Intercomparison Project Phase 3 or Phase 5 (henceforth CMIP3, CMIP5 respectively). "PPE" (see Sect. 3.3) refers to the Perturbed Physics Ensemble of HadCM3 variants as described by Murphy et al. (2007).

In order to be unambiguous and concise regarding each of the contributions to 21 st century sea-level change considered in this study, they are tabulated (Table 1) together with the abbreviations used for each.

Whilst discussing the impacts on the NW European coast we consider the components listed above evaluated within geographical masks formed by the ocean model grid boxes nearest to the coast. Again to avoid ambiguity we tabulate (Table 2) abbreviations which we use for each component as it is evaluated on a particular coast mask.

\section{Models and methods}

\subsection{Contribution from $T E$ and $A D S L$}

For the contributions $T E$ and $A D S L$, we used 11 model projections from the CMIP3 project (see, http://www-pcmdi. llnl.gov/ipcc/about_ipcc.php). This project produced model data that were used in the IPCC Fourth Assessment Report (Meehl et al., 2007; henceforth AR4).

We used 11 of the CMIP3 models. These were selected from the full set of CMIP3 models on the basis that DSL projections under the A1B scenario and the accompanying parallel sections of simulations with fixed greenhouse gas concentration were both available to us (together with global thermal expansion). Using this subset of models therefore allowed a common approach to be taken in removing model drift in the DSL pattern changes. 
Table 2. Definitions and abbreviations used for those components which are evaluated on a local coastal mask.

\begin{tabular}{|c|c|}
\hline Abbreviation & Description \\
\hline$M n \_A D S L$ & $\begin{array}{l}A D S L \text { averaged over the NW Europe } \\
\text { coastal mask shown in Fig. } 2\end{array}$ \\
\hline$M n \_I D S L$ & $\begin{array}{l}\text { IDSL averaged over the NW Europe } \\
\text { coastal mask shown in Fig. } 2\end{array}$ \\
\hline$M n \_G C F F$ & $\begin{array}{l}\text { GCFF averaged over the NW Europe } \\
\text { coastal mask shown in Fig. } 2\end{array}$ \\
\hline Max_GCFF & $\begin{array}{l}\text { Maximum of } G C F F \text { over the NW Europe } \\
\text { coastal mask shown in Fig. } 2\end{array}$ \\
\hline$M n \_S R G$ & $\begin{array}{l}S R G \text { averaged over the high-resolution } \\
\text { coastal mask shown in Fig. } 3\end{array}$ \\
\hline$M a x \_S R G$ & $\begin{array}{l}\text { Maximum of } S R G \text { over the high- } \\
\text { resolution coastal mask shown in Fig. } 3\end{array}$ \\
\hline
\end{tabular}

A common land mask was applied to each of the model $(T E+A D S L)$ projections and a NW European coastally averaged $\left(T E+M n \_A D S L\right)$ then calculated for each model (the masked region is shown in Fig. 2; the values are very similar when using a masked region of half this width), where $M n \_A D S L$ is $A D S L$ averaged over the masked region. We also used $T E$ data for each of the 11 models to partition the sum $\left(T E+M n \_A D S L\right)$ into its components $T E$ and $M n \_A D S L$. This also enabled us to check our distribution of $11 T E$ values against the two percentiles reported in AR4, and to make a basic comparison with the corresponding values in AR5 (see Sect. 4.1).

\subsection{Contribution from TIM and GCFF}

We derived projections of two contributions, TIM and GCFF, from two time series which are the same as those used in Spada et al. (2013). We used expert judgement in the selection of these two time series which we regard as a representative mid-range (MR) and an illustrative high-end (HE) time series taken from a plausible perturbed ice parameter ensemble. Some of the simulations from the full ensemble were deemed unrealistic based on expert judgement. We partitioned each time series into a global mean $\left(T I M^{1}\right)$ and spatially varying component $(G C F F)$. We selected data for the 2080-2099 period, calculating changes with respect to 1992 (see Howard et al., 2014 for further details). This model output was provided on a grid (described by Spada and Stocchi, 2007) with lower resolution than our surge model grid (shown, for example, in Fig. 3). However, this lowerresolution grid does not overlap all the specific coastal sites chosen for this study, and so for each of these sites, we interpolated the low-resolution grid using values from grid points to the east and west (for example around the British

\footnotetext{
${ }^{1}$ This is the global mean contribution due to a change in mass of the oceans, sometimes referred to as the eustatic contribution but more correctly termed the barystatic contribution.
}

Isles). For grid points on the high-resolution grid with no low-resolution point to the east, we used the value for the nearest low-resolution value to the west. This is justified by the fact that, in this region, there is only a small east-west gradient, compared to the dominant north-south gradient in the $G C F F$ component.

\subsection{Contribution from $S R G$}

There is good evidence (e.g. Howard et al., 2010; Sterl et al., 2009) that changes in storm surge contribution to sea level can be added linearly to mean sea-level change and so, following Lowe et al. (2009), that is the approach we took in this study.

Our approach for deriving projections of the contribution of changes in storm surge to extreme sea level also follows that of Lowe et al. (2009). The approach is based on a perturbed atmospheric physics ensemble (PPE) of the HadCM3 global climate model, downscaled by a matching ensemble of perturbed HadCM3 variants in atmospheric regional climate model (RCM) format.

We acknowledge that the uncertainty range of our PPE will not in general encompass the structural uncertainty of the MME that we were able to use for the TE and ADSL contributions. Nevertheless, the range of climate sensitivity exhibited by the PPE is comparable to that of the MME (Collins et al., 2011).

The surface wind and atmospheric pressure fields output by the RCMs were used to drive a barotropic surge model, CS3 (Flather et al., 1998), in combined surge-and-tide mode. A parallel simulation in tide-only mode allows extraction of the non-tidal surge residual or the skew surge. Changing bathymetry due to increasing mean sea level is not included in the surge model but is added linearly in a separate step (this does not include changing coastline due, for example, to newly inundated areas; the land/sea mask does not change). The model integration ran from 1850 to 2100 . The domains of CS3 and the RCM are shown in Fig. 1. CS3 has been extensively validated for the present-day climate (see for example, Lowe et al., 2009).

As in Lowe et al. (2009), we present projections of the "skew surge", which is a good measure of the impact of a surge. It is defined as the difference between the height of the highest water level predicted by the model and the nearestin-time astronomical high tide at the same point. A statistical generalised extreme-value model (Coles, 2001), with linear time trend in the location and scale parameter, was fitted to the five largest independent skew surges in each year (see for example Tawn, 1992; Coles, 2001). From this, we diagnosed a maximum likelihood estimator of the trend in the 50-year return level. Thus our approach allows for the possibility of a linear time trend in the extremes (forced by the changing atmospheric storminess). The magnitude of this trend compared with the corresponding uncertainty gives a measure of the statistical significance. 


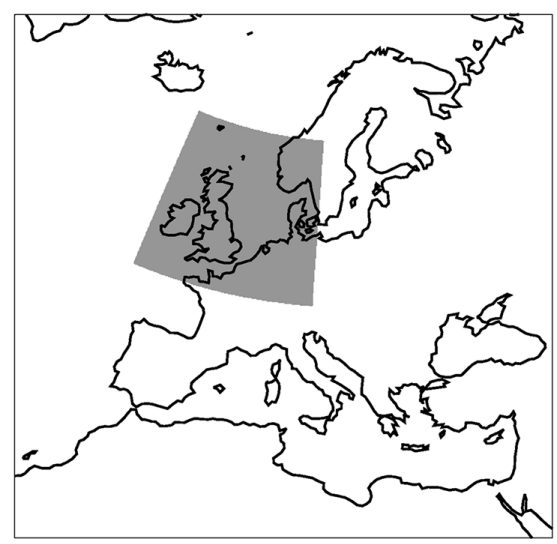

Figure 1. Domain of the storm surge model, CS3 (shaded). The outer frame indicates the domain of the regional atmospheric climate model.

Again, following the approach taken by Lowe et al. (2009), we treated the ensemble member projections as alternative, but equally valid, realisations of a naturally variable future storm surge climate. Under this assumption, it is reasonable to take the mean trend in the ensemble as a representative central projection, and the standard deviation of the ensemble as a measure of spread. Assuming that the 11 trends in the extremes are normally distributed, we could then estimate the 95th percentile of the trend, independently at each location. This assumption is reasonable, even though we do not expect the extremes themselves to be normally distributed. We acknowledge that the approach is limited by the fact that we disregard the spatial dependence in the trends, but argue that it is still reasonable because we make no claims about the joint probability of the spatial patterns.

\section{Results}

\subsection{Contribution from $T E$ and $A D S L$}

Patterns of combined $T E+A D S L$ for 11 members of the CMIP3 MME are shown in Fig. 2, along with the coast mask used to evaluate the local spatial mean (i.e. a spatial mean representative of the NW European coast). The 11 members that we used were: ccma_cgcm3_1_t47, gfdl_cm2_0, gfdl_cm2_1, giss_aom, giss_model_e_h, giss_model_e_r, miroc3_2medres, miub_echo_g, mpi_echam5, mri_cgcm2_3_2a and ukmo_hadcm3. The range of projections of TE reported in AR4 for A1B and for 2090-2099 relative to 1980-1999, were $13 \mathrm{~cm}$ (5th percentile) and $32 \mathrm{~cm}$ (95th percentile), giving a mean of $22.5 \pm 5.8 \mathrm{~cm}$, where the uncertainty is expressed as a standard deviation assuming a normal distribution. The corresponding value from our 11-member ensemble is $21.4 \pm 5.5 \mathrm{~cm}$. For this contribution, the agreement is very good, and so it makes little difference whether we adjust
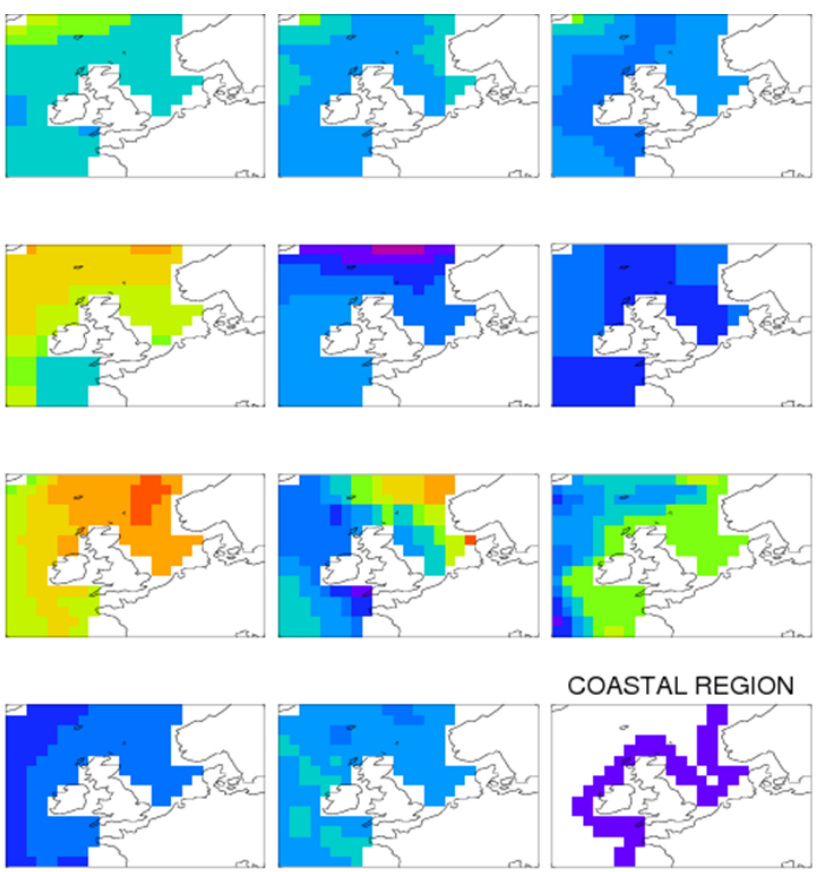

COASTAL REGION

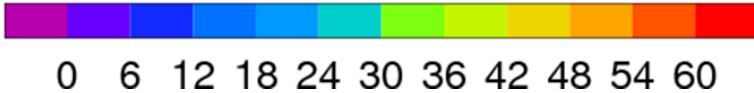

Figure 2. $(T E+A D S L)$ in centimetres for the NW European region derived from 11 CMIP3 models. Projections are for the SRES A1B scenario and for the period 2080-2099 relative to 1980-1999. The lower right frame shows the mask used to extract $M n \_A D S L$.

our estimates to take account of the range quoted in AR4 or not; however, we have made this adjustment in order to take advantage of the additional information used in AR4 (the TE range quoted in AR4 comes from more than 11 models). This ensured that our approach, applied to the NW European coastline, was consistent with the methodology used previously (Lowe et al., 2009). The adjustment consists of replacing the 11-member mean and variance of $T E$ $\left(21.4 \mathrm{~cm}\right.$ and $\left.30.25 \mathrm{~cm}^{2}\right)$ with the corresponding values from AR4 $\left(22.5 \mathrm{~cm}\right.$ and $\left.33.64 \mathrm{~cm}^{2}\right)$. We also made a consistent adjustment to the mean and variance of the sum $(T E+$ $M n \_A D S L$ ), whilst preserving the covariance as given by the 11 ensemble members. Although the agreement between the 11-member $T E$ and the range of projections of $T E$ reported in AR4 is very good, we acknowledge that with the available data we cannot know how well our 11-member assessment of the Mn_ADSL contribution would match that of the full MME, if suitable data were available to calculate it. For each of the 11 members, the partitioning of the sum (TE + $M n \_A D S L$ ) into its components $T E$ and $M n \_A D S L$ is shown by the dotted points in Fig. 4.

A direct comparison with CMIP5 results is not possible due to the different approach to emissions in AR5 compared to AR4, however we note that both mean and the spread of 
(a)

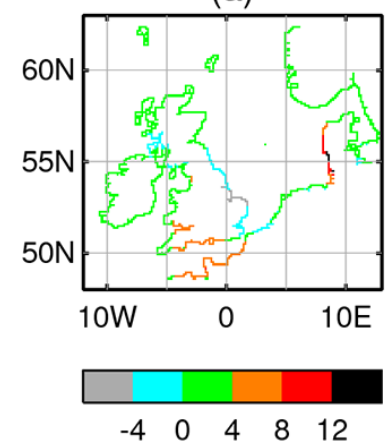

(b)

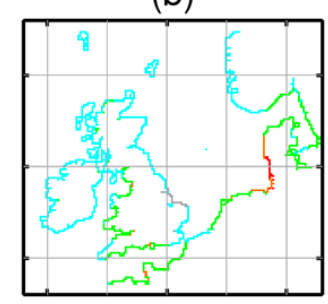

$0 \quad 5 \quad 101520$

Figure 3. Projected contribution in centimetres of the change in storm surge climate to 21 st century change in the 50 -year return storm surge for (a) central estimate, (b) 95th percentile. Both are given in terms of the skew surge above astronomical high tide, and represent the contribution due to atmospheric storminess changes only.

$\left(T E+M n \_A D S L\right)$ are comparable to the values for the NW European region given in AR5 under RCP4.5 (Church et al., 2014; their Fig. 13.16).

\subsection{Contribution from TIM and GCFF}

Patterns of these contributions are not shown here because they are similar to those presented previously (Spada et al., 2013). The TIM contributions are $20 \mathrm{~cm}$ (mid-range) and $50 \mathrm{~cm}$ (high-end).

\subsection{Contribution from $S R G$}

The projected component of extreme water level changes due only to changes in storm surge climate is shown in Fig. 3. We note that the pattern is broadly consistent with the expected increase in the frequency and/or intensity of westerly or southwesterly winds. This is addressed further in the discussion section below.

\section{Comparison and addition of contributions}

The distribution of values, shown in Fig. 4, allows us to explore the relative significance of the various contributions to 21 st century extreme sea-level change around NW Europe.

The contributions shown in Fig. 4 come from very different types of model and in general their error covariances are not known (the exception is TE and Mn_ADSL, see below). Furthermore, the HE TIM member is selected as an illustrative high-end realisation with an unquantified probability of exceedance. Nevertheless, previous studies (e.g. Sterl et al., 2009; Howard et al., 2010) have shown that it is reasonable to combine surge changes additively with mean sealevel change. Similarly Howard et al. (2014) show that for their model IDSL and ADSL changes appear to be additive.

(a)
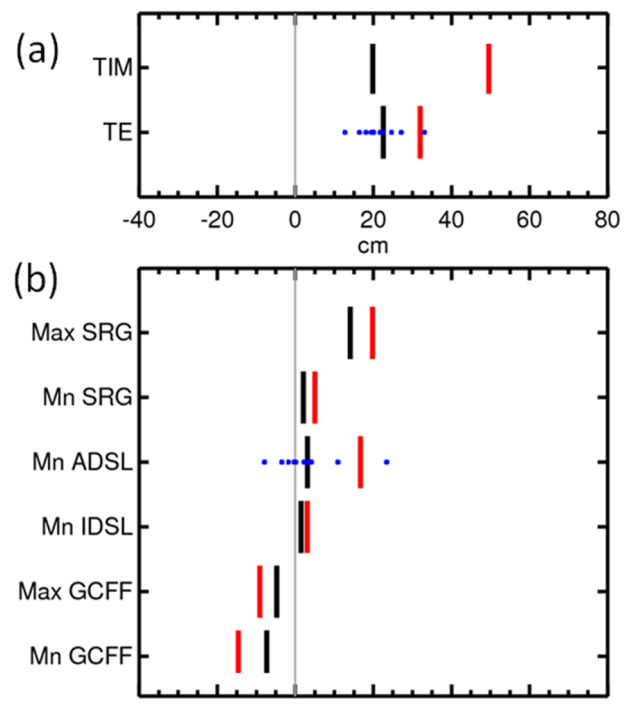

Figure 4. Comparison of contributions to the 21st century change in 50-year storm surge height around NW Europe (centimetres). (a) Global mean contributions, (b) local contributions. Black bars indicate the representative mid-range, and red, the illustrative highend contributions. Blue dots show the individual ensemble members where these are available. The abbreviations used in the figure are those given in Tables 1 and 2 .

Therefore we present an illustrative addition of HE contributions to the change in the height of the 50-year storm surge, for seven locations around NW Europe in Fig. 5. The locations are Aberdeen, Sheerness, Cork Harbour, Roscoff, The Hague, Esbjerg and Bergen. Again the abbreviations used for the contributions are those of Tables 1 and 2. Note that the HE contribution from (TE + Mn_ADSL) is not simply the sum of the HE TE and HE Mn_ADSL contributions shown in Fig. 4 because in the case of these two contributions only we do know about their covariance and we can select a HE value directly from the distribution of their sum.

\section{Discussion}

Under our representative mid-range projection we found that $T E$ and TIM are the largest contributors to 21 st century extreme sea-level change around NW Europe (Figs. 4 and 5). However, the largest uncertainties arise from TIM, and TIM made the largest contribution to the illustrative high-end projection. The uncertainty due to $M n \_A D S L$ was also large. Within the limitations of our method (i.e. the use of only one model formulation with two different meltwater forcings), we found both contribution and uncertainty to be very small for Mn_IDSL (MR: $1.4 \mathrm{~cm}$; HE: $3 \mathrm{~cm}$ ). The $S R G$ contribution is important in some locations, though within the limitations of our $S R G$ modelling approach, it appeared to be relatively well-constrained (see Sect. 6.1). Spatial variations due to $S R G$ and GIA are both considerable. 
Table 3. High-end 21st century sea-level change figures taken from Lowe et al. (2009), Katsman et al. (2011) and this study. The Lowe et al. figures are the top of the range of their " $\mathrm{H}++$ " scenario, with "Local" referring to the coast of the UK. The Katsman figures are the top of the range of their high-end scenario, with "Local" referring to the coast of the Netherlands. For this study the "Local" figure refers to The Hague. Figures for Lowe et al. (2009) and for this study exclude both GIA and SRG because these were not treated in the same way in all three studies.

\begin{tabular}{lll}
\hline Lowe et al. "H++" & Global & $2.5 \mathrm{~m}$ \\
& Local (UK) & $1.9 \mathrm{~m}$ \\
Katsman et al. A1FI & Global & $1.15 \mathrm{~m}$ \\
& Local (Netherlands) & $1.05 \mathrm{~m}$ \\
\multirow{2}{*}{ This study A1B, HE } & Global & $0.82 \mathrm{~m}$ \\
& Local (The Hague) & $0.84 \mathrm{~m}$ \\
\hline
\end{tabular}

In Table 3 we compare illustrative high-end projections from our study with two other studies addressing sea-level change around the coast of NW Europe. In order to make a like-for-like comparison we exclude contributions from $S R G$ and GIA in Table 3 because these contributions were addressed differently in the three studies. The IPCC AR5 (Church et al., 2013) note that there is low agreement within semi-empirical model projections and no consensus in the scientific community about their reliability. Thus we have not quoted projections from such models here. However, for a summary of such projections in comparison to processbased projections the reader may see for example Nicholls et al. (2011).

Lowe et al. (2009) provide a mostly process-based projection $^{2}$ of sea-level rise for the coast of the UK (with which our TE, GIA, ADSL and SRG contributions are all consistent). However, Lowe et al. (2009) also offer a (partly proxy-based) projection for vulnerability testing, their so-called " $\mathrm{H}++$ " scenario range. It is informative to compare this scenario with our results (Table 3 ), although the $\mathrm{H}++$ range was intended to look at plausible upper limits based partly on proxy data and it should be borne in mind that recent observations and model projections do not provide any evidence to suggest that such high levels of sea-level rise will occur within the 21 st century. Church et al. (2013), acknowledging that the potential additional contribution to global mean sea-level rise from the collapse of marine-based sectors of the Antarctic Ice Sheet cannot be precisely quantified, judge that there is "medium confidence that it would not exceed several tenths of a metre of sea level rise during the 21 st century".

Katsman et al. (2011) developed a plausible scenario of high-end 21st century sea-level rise for both the global mean and for the coast of the Netherlands under the A1FI emissions scenario. Owing to the different approach and different emissions scenario, our results are not directly comparable but comparison for the global and regional total is possible

\footnotetext{
${ }^{2}$ Their projection of ice sheet behaviour was not process based.
}
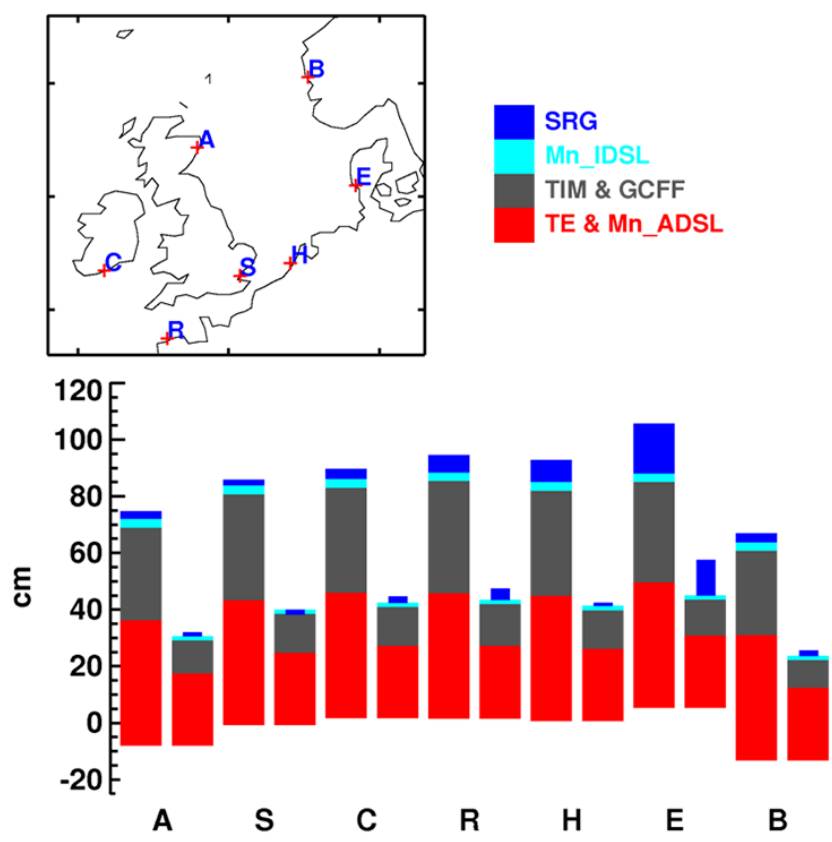

Figure 5. Addition of illustrative high-end (and representative midrange) projections of contributions to 21 st century change in the height of the 50-year storm surge for seven locations around NW Europe. The locations are Aberdeen, (A); Sheerness, (S); Cork Harbour (C); Roscoff, (R); The Hague, (H); Esbjerg (E) and Bergen (B). For each location, the larger (left-hand) bar shows the high-end estimate, and the smaller (right-hand) bar shows the mid-range estimate. The projected contribution from GIA is shown as an offset to the zero of each bar. The mid-range $S R G$ projection at Sheerness is negative, and so that this can be seen, the mid-range $S R G$ projections are shown as half-width bars. Further details are given in the main text.

(Table 3). The differences between the Katsman figures and this study are mostly due to the larger projected contribution from the Antarctic ice sheet in the "severe" scenario used in Katsman et al. (2011). However, it is also noticeable that the local sea-level rise is greater than the global mean in our study, but smaller in the other two. The main reason for this is the smaller contribution from the Greenland ice sheet in our projections (see Howard et al., 2014). (The fingerprint of Greenland melt is characterised by less-than-global-mean increases around NW Europe).

Our TE and Mn_ADSL contributions are taken from the CMIP3 models and have been discussed elsewhere (e.g. Pardaens et al., 2011; Landerer et al., 2007; Lowe and Gregory, 2006; Suzuki et al., 2005). Our TIM and Mn_GCFF are based on work described in Spada et al. (2013). Our $M n \_I D S L$ contribution is discussed extensively by Howard et al. (2014). Consequently, we focus here on the $S R G$ contribution for NW Europe. 


\subsection{Changes in surges}

Following Lowe et al. (2009) we assessed the local statistical significance of the $S R G$ contribution by comparing the PPE mean with the PPE spread. We considered a range of geographically distributed locations (shown in Fig. 5). We found that the $S R G$ contribution was positive and locally statistically significant in this sense at Aberdeen, Cork Harbour, Roscoff, Esbjerg and Bergen ( $p$ value less than 0.05, onesided test).

The changes in $T E$ and $A D S L$ (Fig. 2) were based on the CMIP3 MME, whereas the surge changes were based on the more limited PPE. Despite this, even under the limited range of changes in storminess emerging from the PPE, we find that surge changes are a significant contributor in some locations. Surge changes are critically dependent on changes in atmospheric storminess and it should be borne in mind that previous work has shown that the range of storminess changes emerging from the PPE in our region of concern are smaller than those emerging from the CMIP3 MME (Lowe et al., 2009). As a consequence, the surge changes could be more important than implied by Fig. 5 under a more comprehensive multi-model assessment (see Lowe et al., 2009 chapter 4, for their discussion of the "H++" approach).

A general pattern of a projected increase in storm surge extremes in the eastern North Sea, particularly on the westfacing coast of the Jutland Peninsula (Fig. 3), in contrast to a much smaller signal on the east coast of the UK, can be seen in projections made by a number of previous studies (based on emissions scenarios including A1B, A2 and B2), e.g. Gaslikova et al. (2013), Debernard and Røed (2008), Woth (2006) and Lowe and Gregory (2005, in particular their projection for the B2 scenario). These previous studies, however, used only single realisations or small ensembles, typically combined with a comparison of two 30-year time slices representing the projection and the present day respectively. Such an approach is susceptible to aliasing information from natural multi-decadal variations in storminess over the region (see for example Jenkins et al., 2008, in particular their Fig. 1.14). Some recent studies (e.g. Sterl et al., 2009; Lowe et al., 2009) have addressed this issue by using larger model ensembles and/or considering the linear change in storm surge characteristics over the full period of the simulation, typically 150 years. We use both approaches here. Consistent with Sterl et al. (2009) we find no significant increase in storm surge characteristics on the Dutch coast. As noted by Sterl et al. (2009) this in turn is not inconsistent with an increase in westerly or southwesterly winds, which do not tend to produce severe surges on that coast.

\subsection{Surge change relationship with wind changes}

Sterl et al. (2009) projected a small increase in maximum wind speeds over the southern North Sea over the 21st century, noting that since this was due to winds from the south- west it may not lead to a significant increase in surge heights along the Dutch coast. Our model results support this conclusion for the Dutch coast; for example, we find a small, statistically insignificant increase in surge amplitude at The Hague. We also note that the larger (and in some areas statistically significant) trends in the ensemble-mean surge projections are mostly on west or southwest facing coasts, broadly consistent with an increase in the westerly or southwesterly component of wind. However, there is no strong signal of winter mean wind speed change in our PPE (see for example Brown et al. (2009), particularly their Fig. 10 referring to the UK or their Fig. 13a which refers to the entire RCM domain). In validating their driving climate models Sterl et al. (2009) and Howard et al. (2010) consider the annual maximum daily mean wind speed at $5^{\circ} \mathrm{E}, 55^{\circ} \mathrm{N}$. We looked at our model relationship between this quantity and the changing surge levels at Esbjerg, where some of the largest changes are projected. We find a statistically significant but weak correlation between modelled annual maximum daily mean wind speed at $5^{\circ} \mathrm{E}, 55^{\circ} \mathrm{N}$ and the modelled annual maximum skew surge at Esbjerg (Pearson's $r=0.2, p$ value less than 0.001 over the 150 years of model simulation, using data from all $11 \mathrm{mem}$ bers of the PPE) and a weak correlation between the centuryscale change in the 50 year return level of daily mean wind speed at $5^{\circ} \mathrm{E}, 55^{\circ} \mathrm{N}$ (11 values, one from each PPE ensemble member) and the century-scale change in the 50-year return level of skew surge at Esbjerg (11 values, one from each PPE ensemble member; $r=0.37, p$ value 0.26 ). Our ensemble mean projected century-scale change in the 50-year return level of daily mean wind speed at $5^{\circ} \mathrm{E}, 55^{\circ} \mathrm{N}$ is of the order of $10 \mathrm{~cm}$ per second over the $21 \mathrm{st}$ century (90\% confidence interval of $[-16,37]$ centimetres per second per century). Although this is consistent with the increase in surge amplitude at The Hague, in view of the weak correlation it is of limited utility in explaining the increase. Many other factors need to be considered: wind direction, duration, spatial extent and storm track, for example. Such an analysis is beyond the scope of the present work.

Gaslikova et al. (2013) report somewhat similar patterns of projected storm surge change to ours under the A1B emissions scenario and their changes appear to be related to their reported increase in both the annual 99th percentile of wind speed and the frequency of occurrence of westerly or southwesterly winds with speeds greater than $17.2 \mathrm{~m} \mathrm{~s}^{-1}$, both change assessments being based on the 30-year time slice approach. De Winter et al. (2013) consider projections of 12 members of the CMIP5 ensemble and they also find an indication of annual extreme winds over the North Sea coming more often from western directions. 


\section{Conclusions}

In this study, we compared representative mid-range and illustrative high-end projections of 21 st century contributions to extreme sea-level change around NW Europe. These contributions arise from changes in atmospheric storminess, terrestrial ice melt from ice sheets and glaciers, thermal expansion of the oceans, changes in dynamic sea level associated with the projected ice loss, and with projected climate change, and effects of glacial isostatic adjustment associated with loss of ice since the Last Glacial Maximum. As far as possible we have used projections based on the SRES A1B emissions scenario to provide a self-consistent, processbased model-derived set of projections of mean sea-level rise and changes in extreme surge levels expressed as the change in the height of the 50 year flood. In regard to sea-level rise, the A1B scenario is broadly similar to both representative concentration pathways RCP4.5 and RCP6.0, which differ only in the latter half of the 21 st century.

We find that the largest sources of uncertainty within these single-emission-scenario simulations are in the contribution from dynamic sea-level changes associated with the direct warming effects of radiative forcing, and the global mean contribution of ice loss. Our approach does have some limitations; for example, our analysis of the changing distribution of surges is based on a perturbed-physics ensemble generated by a single model, rather than a multi-model ensemble. Nevertheless, we find that the change in the statistical distribution of surges (associated with changes in their atmospheric forcing only) contributes significantly to the spatial variations in the projected changes of the 50-year flood height, and in some locations may make a significant contribution, particularly along parts of the European mainland coast not considered by Lowe et al. (2009). For example, our central estimate of this contribution to the rise in the 21 st century extreme sea level on the west coast of the Jutland Peninsula is $15 \mathrm{~cm}$, which can be compared with a central estimate of around $22 \mathrm{~cm}$ from global mean thermal expansion.

Acknowledgements. This work was supported by funding from the ice2sea programme from the European Union 7th Framework Programme, grant number 226375. Ice2sea contribution number \#164. This work was also supported by the Joint UK DECC/Defra Met Office Hadley Centre Climate Programme (GA01101). We acknowledge the significant contribution made by Kevin Horsburgh and his colleagues at the National Oceanography Centre. We thank the two anonymous reviewers whose comments helped to improve this paper.

Edited by: A. Sterl

\section{References}

Araujo, I. B. and Pugh, D. T.: Sea levels at Newlyn 1915-2005: analysis of trends for future flooding risks, J. Coastal Res., 24, 203-212, doi:10.2112/06-0785.1, 2008.

Brown, S., Boorman, P., McDonald, R., and Murphy, J.: Use and interpretation of surface wind projections from the 11-member Met Office Regional Climate Model ensemble, UKCP09 Technical Note. Met Office Hadley Centre, Exeter, UK, available at: http://ukclimateprojections.defra.gov.uk (last access: 12 December 2013), 2009.

Church, J. A., Clark, P. U., Cazenave, A., Gregory, J. M., Jevrejeva, S., Levermann, A., Merrifield, M. A., Milne, G. A., Nerem, R. S., Nunn, P. D., Payne, A. J., Pfeffer, W. T., Stammer, D., and Unnikrishnan, A. S.: Sea level change, in: Climate Change 2013: The Physical Science Basis Contribution of Working Group I to the Fifth Assessment Report of the Intergovernmental Panel on Climate Change, edited by: Stocker, T. F. Qin, D., Plattner, G.-K., Tignor, M., Allen, S. K., Boschung, J., Nauels, A., Xia, Y., Bex, V., and Midgley, P. M., Cambridge University Press, Cambridge, UK and New York, NY, USA, in press, 2013.

Coles, S.: An introduction to statistical modeling of extreme values, Springer, 208 pp., 2001.

Collins, M, Booth, B. B. B., Bhaskaran, B, Harris, G. R., Murphy, J. M., Sexton, D. M. H., and Webb, M. J.: Climate model errors, feedbacks and forcings: a comparison of perturbed physics and multi-model ensembles, Clim. Dynam., 36, 1737-1766, doi:10.1007/s00382-010-0808-0, 2011.

Debernard, J. B. and Roed, L. P.: Future wind, wave and storm surge climate in the Northern Seas: a revisit, Tellus A, 60, 427-438, doi:10.1111/j.1600-0870.2008.00312.x, 2008.

de Winter, R. C., Sterl, A., and Ruessink, B. G.: Wind extremes in the North Sea Basin under climate change: An ensemble study of 12 CMIP5 GCMs, J. Geophys. Res.-Atmos., 118, 1601-1612, doi:10.1002/jgrd.50147, 2013.

Flather, R. A., Smith, J. A., Richards, J. D., Bell, C., and Blackman, D. L.: Direct estimates of extreme storm surge elevations from a $40 \mathrm{yr}$ numerical model simulations and from observations, The Global Atmos. Ocean Syst., 6, 165-176, 1998.

Gaslikova, L., Grabemann, I., and Groll, N.: Changes in North Sea storm surge conditions for four transient future climate realizations, Nat. Hazards, 66, 1501-1518, doi:10.1007/s11069-0120279-1, 2013.

Giesen, R. H. and Oerlemans, J.: Climate-model induced differences in the 21 st century global and regional glacier contributions to sea-level rise, Clim. Dynam., 41, 1-18, 2013.

Goelzer, H., Huybrechts, P., Fürst, J. J., Nick, F. M., Andersen, M. L., Edwards, T. L., Fettweis, X., Payne, A. J., and Shannon, S. R.: Sensitivity of Greenland ice sheet projections to model formulations, J. Glaciol., 59, 733-749, 2013.

Haigh, I., Nicholls, R., and Wells, N.: Assessing changes in extreme sea levels: application to the English Channel, 1900-2006, Cont. Shelf. Res., 30, 1042-1055, doi:10.1016/j.csr.2010.02.002, 2010.

Howard, T., Lowe, J., and Horsburgh, K.: Interpreting centuryscale changes in Southern North Sea storm surge climate derived from coupled model simulations, J. Climate, 23, 62346247, doi:10.1175/2010jcli3520.1, 2010. 
Howard, T., Ridley, J., Pardaens, A. K., Hurkmans, R. T. W. L., Payne, A. J., Giesen, R. H., Lowe, J. A., Bamber, J. L., Edwards, T. L., and Oerlemans, J.: The land-ice contribution to 21st-century dynamic sea level rise, Ocean Sci., 10, 485-500, doi:10.5194/os-10-485-2014, 2014.

Jenkins, G. J., Perry, M. C., and Prior, M. J.: The climate of the UK and recent trends. Met Office Hadley Centre, Exeter, UK, available at: http://ukclimateprojections.defra.gov.uk (last access: 12 December 2013), 2008.

Katsman, C. A., Sterl, A., Beersma, J. J., van den Brink, H. W., Church, J. A., Hazeleger, W., Kopp, R. E., Kroon, D., Kwadijk, J., Lammersen, R., Lowe, J., Oppenheimer, M., Plag, H. P., Ridley, J., von Storch, H., Vaughan, D. G., Vellinga, P., Vermeersen, L. L. A., van de Wal, R. S. W., and Weisse, R.: Exploring high-end scenarios for local sea level rise to develop flood protection strategies for a low-lying delta-the Netherlands as an example, Climatic Change, 109, 617-645, doi:10.1007/s10584-011-0037-5, 2011.

Kuhlbrodt, T. and Gregory, J. M.: Ocean heat uptake and its consequences for the magnitude of sea level rise and climate change, Geophys. Res. Lett., 39, L18608, doi:10.1029/2012GL052952, 2012.

Landerer, F. W., Jungclaus, J. H., and Marotzke, J.: Regional Dynamic and Steric Sea Level Change in Response to the IPCC-A1B Scenario, J. Phys. Oceanogr., 37, 296-312, doi:10.1175/JPO3013.1, 2007.

Lempérière, F.: The role of dams in the XXI century: achieving a sustainable development target, International Journal on Hydropower and Dams, 13, 99-108, 2006.

Lettenmaier, D. P. and Milly, P. C. D.: Land waters and sea level, Nature Geosci., 2, 452-454, doi:10.1038/ngeo567, 2009.

Ligtenberg, S. R. M., van de Berg, W. J., van den Broeke, M. R., Rae, J. G. L., and van Meijgaard, E.: Future surface mass balance of the Antarctic ice sheet and its influence on sea level change, simulated by a regional atmospheric climate model, Clim. Dynam., 41, 867-884. doi:10.1007/s00382-013-1749-1, 2013.

Lowe, J. A. and Gregory, J. M.: The effects of climate change on storm surges around the UK, Philos. T. R. Soc., 363, 1313-1328, doi:10.1098/rsta.2005.1570, 2005.

Lowe, J. A. and Gregory, J. M.: Understanding projections of sea level rise in a Hadley Centre coupled climate model. J. Geophys. Res., 111, C11014, doi:10.1029/2005JC003421, 2006.

Lowe, J. A., Howard, T. P., Pardaens, A., Tinker, J., Holt, J., Wakelin, S., Milne, G., Leake J, Wolf, J., Horsburgh, K., Reeder, T., Jenkins, G., Ridley, J., Dye, S., and Bradley, S.: UK Climate Projections science report: Marine and coastal projections, Met Office Hadley Centre, Exeter, UK, available at: http://ukclimateprojections.defra.gov.uk (last access: 12 December 2013), 2009.

Meehl, G. A., Stocker, T. F., Collins, W. D., Friedlingstein, P., Gaye, A. T., Gregory, J. M., Kitoh, A., Knutti, R., Murphy, J. M., Noda, A., Raper, S. C. B., Watterson, I. G., Weaver, A. J., and Zhao, Z.: Global climate projections, in: Climate change 2007: The Physical Science Basis, Contribution of Working Group I to the Fourth Assessment Report of the Intergovernmental Panel on Climate Change, edited by: Solomon, S., Qin, D., Manning, M., Chen Z, Marquis, M., Averyt, K. B., Tignor, M., and Miller, H. L., Cambridge University Press, London, 2007.
Mudersbach, C., Wahl, T., Haigh, I. D., and Jensen, J.: Trends in high sea levels of German North Sea gauges compared to regional mean sea level changes, Cont. Shelf Res., 65, 111-120, doi:10.1016/j.csr.2013.06.016, 2013.

Muller, M., Arbic, B. K., and Mitrovica, J. X.: Secular trends in ocean tides: Observations and model results, J. Geophys. Res.Oceans, 116, C05013, doi:10.1029/2010JC006387, 2011.

Murphy, J. M., Booth, B. B. B., Collins, M., Harris, G. R., Sexton, D. M. H., and Webb, M. J.: A methodology for probabilistic predictions of regional climate change from perturbed physics ensembles, Philos. T. R. Soc. A, 365, 1993-2028, doi:10.1098/rsta.2007.2077, 2007.

Nicholls, R. J., Marinova, N., Lowe, J. A., Brown, S., Vellinga, P., De Gusmao, D., Hinkel, J., and Tol, R. S. J.: Sealevel rise and its possible impacts given a "beyond $4{ }^{\circ} \mathrm{C}$ world" in the twenty-first century, Philos. T. R. Soc. A, 369, 161-181, doi:10.1098/rsta.2010.0291, 2011.

Nick, F. M., Vieli, A., Andersen, M. L., Joughin, I., Payne, A., Edwards, T. L., Pattyn, F., and van de Wal, R. S. W.: Future sea-level rise from Greenland's main outlet glaciers in a warming climate, Nature, 497, 235-238, doi:10.1038/nature12068, 2013.

Pardaens, A. K., Gregory, J. M., and Lowe, J. A.: A model study of factors influencing projected changes in regional sea level over the twenty-first century. Climate Dynamics 36, 2015-2033, doi:10.1007/s00382-009-0738-x, 2011.

Peltier, W. R.: Global glacial isostasy and the surface of the ice-age earth: The ice-5G (VM2) model and grace, Annu. Rev. Earth Pl. Sc., 32, 111-149, doi:10.1146/annurev.earth.32.082503.144359, 2004.

Pickering, M. D., Wells, N. C., Horsburgh, K. J., and Green, J. A. M.: The impact of future sea-level rise on the European Shelf tides, Cont. Shelf Res., 35, 1-15, doi:10.1016/j.csr.2011.11.011, 2012.

Shannon, S. R., Payne, A. J., Bartholomew, I. D., van den Broeke, M. R., Edwards, T. L., Fettweis, X., Gagliardini, O., GilletChaulet, F., Goelzer, H., Hoffman, M. J., Huybrechts, P., Mair, D. W. F., Nienow, P. W., Perego, M., Price, S. F., Smeets, C. J. P. P., Sole, A. J., van de Wal, R. S. W., and Zwinger, T: Enhanced basal lubrication and the contribution of the Greenland ice sheet to future sea-level rise, Proc. Natl. Acad. Sci. USA, 110, 1415614161, doi:10.1073/pnas.1212647110, 2013.

Slangen, A. B. A., Katsman, C. A., van de Wal, R. S. W., Vermeersen, L. L. A., and Riva, R. E. M.: Towards regional projections of twenty-first century sea-level change based on IPCC SRES scenarios, Clim. Dynam., 38, 1191-1209, doi:10.1007/s00382-011-1057-6, 2012.

Spada, G. and Stocchi, P.: SELEN: a Fortran 90 program for solving the "sea-level equation", Comput. Geosci., 33, 538-562, doi:10.1016/j.cageo.2006.08.006, 2007.

Spada, G., Bamber, J. L., and Huurkmans, R.: The gravitationallyconsistent fingerprint of future terrestrial ice loss, Geophys. Res. Lett., 40, 482-486, doi:10.1029/2012GL053000, 2013.

Sterl, A., van den Brink, H., de Vries, H., Haarsma, R., and van Meijgaard, E.: An ensemble study of extreme storm surge related water levels in the North Sea in a changing climate, Ocean Sci., 5, 369-378, doi:10.5194/os-5-369-2009, 2009.

Suzuki, T., Hasumi, H., Sakamoto, T. T., Nishimura, T., Abe-Ouchi, A., Segawa, T., Okada, N., Oka, A., and Emori, S.: Projection of future sea level and its variability in a high-resolution 
climate model: Ocean processes and Greenland and Antarctic ice-melt contributions, Geophys. Res. Lett., 32, L19706, doi:10.1029/2005GL023677, 2005.

Tawn, J.: Estimating Probabilities of Extreme Sea Levels, Appl. Stat., 41, 77-93, 1992.

Vizcaíno, M., Mikolajewicz, U., Jungclaus, J., and Schurgers, G.: Climate modification by future ice sheet changes and consequences for ice sheet mass balance, Clim. Dynam., 34, 301-324, 2010.

Wahl, T. F., Calafat, M., and Luther, M. E.: Rapid changes in the seasonal sea level cycle along the US Gulf coast from the late 20th century, Geophys. Res. Lett., 41, 491-498, doi:10.1002/2013GL058777, 2014.

Weisse, R., von Storch, H., Niemeyer, H. D., and Knaack, H.: Changing North Sea storm surge climate: an increasing hazard?, Ocean Coast. Manage., 68, 58-68, doi:10.1016/j.ocecoaman.2011.09.005, 2012.
Woodworth, P. L.: A survey of recent changes in the main components of the ocean tide, Cont. Shelf Res., 30, 1680-1691, doi:10.1016/j.csr.2010.07.002, 2010.

Woodworth, P. L. and Blackman, D. L.: Evidence for systematic changes in extreme high waters since the mid1970s, J. Climate, 17, 1190-1197, doi:10.1175/15200442(2004)017<1190:efscie>2.0.CO;2, 2004.

Woth, K., Weisse, R., and von Storch, H.: Climate change and North Sea storm surge extremes: an ensemble study of storm surge extremes expected in a changed climate projected by four different regional climate models, Ocean Dynam., 56, 3-15, doi:10.1007/s10236-005-0024-3, 2006. 